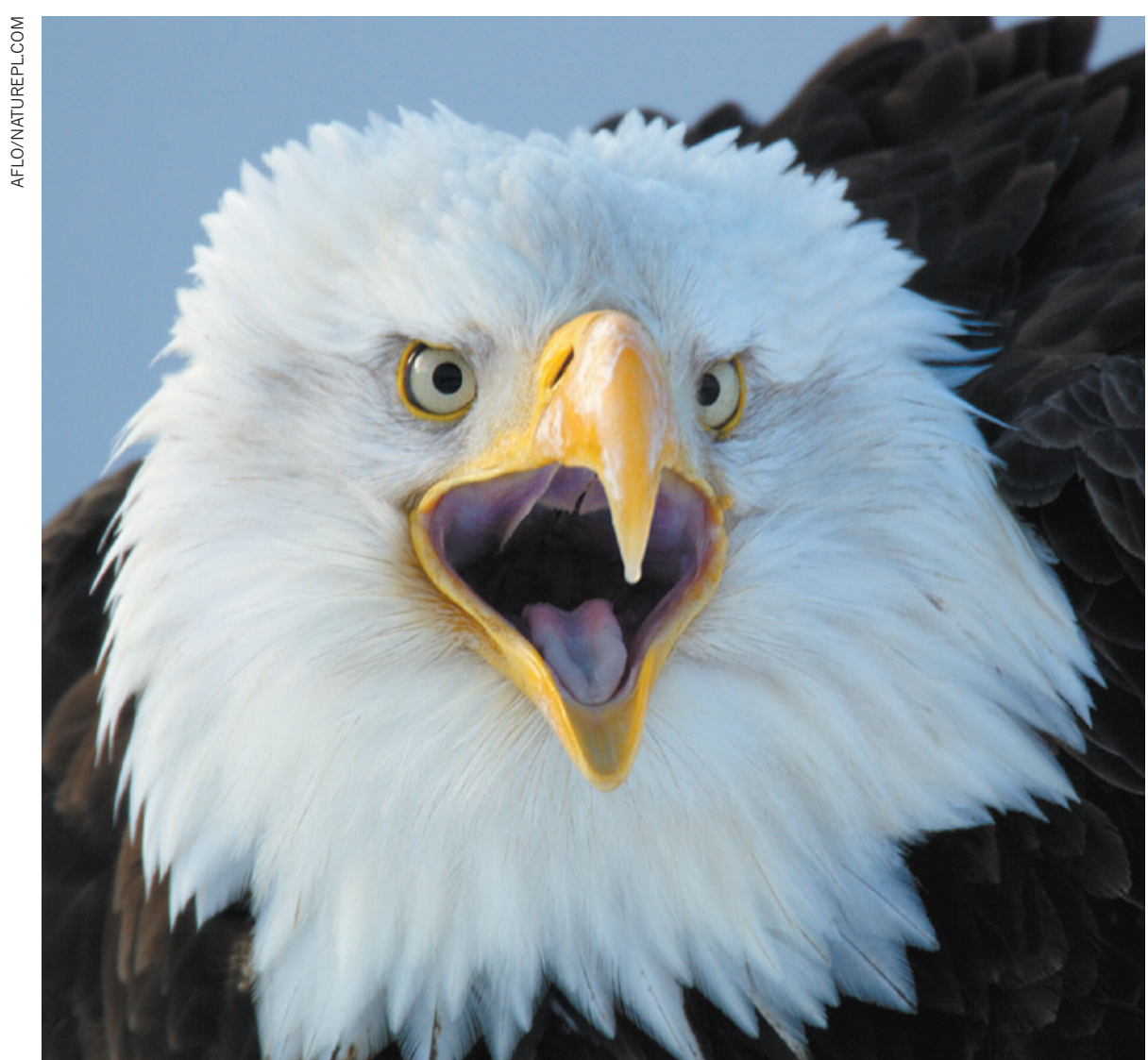

\title{
The Endangered Species Act at 40
}

On the anniversary of a landmark piece of US legislation, four experts weigh in on what has worked and what needs to change.

\section{NOAH GREENWALD Cherish the act's proven power}

\section{Endangered species programme director, Center for Biological Diversity}

The US Endangered Species Act (ESA) is the reason that there are bald eagles from coast to coast, grizzly bears in the Yellowstone ecosystem and American alligators in the southeastern United States. The act remains our best tool for saving species and their habitats and practically our only way of helping declining populations to recover.

Since it came into effect in 1973, the
ESA has had unqualified success at saving species from extinction. So far, only ten of the more than 1,500 species protected under the ESA (see 'On the list') have gone extinct, and eight of these were probably extinct before they received protection. A 2006 analysis ${ }^{1}$ found that, were it not for the ESA, as many as 227 US species would have disappeared.

This landmark law is also putting animals and plants on the path to recovery. An analy$\operatorname{sis}^{2}$ of all federally protected species in the northeast found that more than $90 \%$ were stabilized or improving since being put on the list; more than $80 \%$ were on track to meet recovery goals set by scientists.

The ESA has been criticized for mandating protection of individual species rather than of ecosystems. Yet it has driven some

of the most successful efforts in ecosystem management, most notably the Northwest Forest Plan adopted in 1994. These land-use policies have protected forested and aquatic habitats for northern spotted owls, marbled murrelets and Pacific salmonids.

Too often, those who advocate moving away from the firm protections of the act argue for flexible ecosystem management not to advance conservation, but to avoid economic conflicts. In practice, saving a species can mean saving an entire ecosystem. That helps wildlife and people who depend on clean water, clean air and the other benefits that functioning ecosystems provide.

\section{AMYW. ANDO Focus on the bigger picture}

Professor of environmental and natural resource economics, University of Illinois at Urbana-Champaign

The ESA has accomplished important victories. However, it causes regulators to stand by until species are near the brink of extinction, and so engenders counterproductive cycles of support and endangerment. Protection can be withdrawn without eliminating the forces that led the species to be imperilled. The ESA can help species threatened by direct human action such as hunting. But most species are in decline because of diffuse threats such as invasive species, large-scale land conversion and climate change, over which the act has little power. Efforts to use the ESA to protect the polar bear (Ursus

"Policies to protect individual species should not be based on indiscriminate rules."

maritimus) from melting sea ice cannot, for example, force an international agreement on greenhouse-gas emissions.

Furthermore, a conservation policy that counts all species as having equal value can be counterproductive. Mandatory expenditures perceived by the public as having little value could exhaust society's desire to commit resources to conservation and actually reduce the sum of government and private citizens' conservation efforts. For instance, ESA policies to preserve a small, unalluring fish known as the delta smelt (Hypomesus transpacificus) has led to controversial water-use restrictions in California, feeding anti-conservation sentiment.

Policies to protect individual species should not be based on indiscriminate 


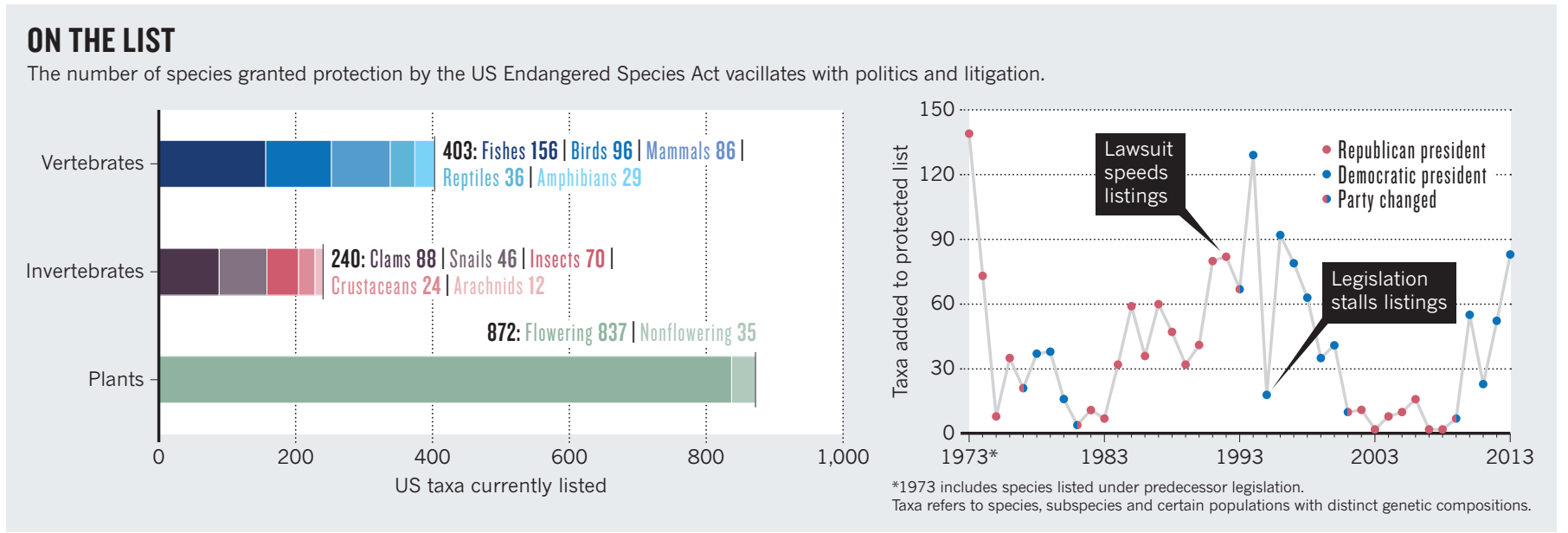

rules. They should be justified case by case, according to the value society places on the species, either for the part it plays in a natural community, or because of the place it holds in people's hearts and lives. For example, freshwater mussels filter out dangerous bacteria; sea turtles inspire awe with their epic migrations. Effective and secure conservation policy will acknowledge these different types of value.

\section{STUART BUTCHART Clarify extinction risk}

\section{Head of science, BirdLife International}

The ESA is one of the most powerful pieces of nature legislation in the world. But it has shortcomings. The act's criteria for listing species as threatened and endangered are remarkably vague. Classifications include terms that lack precise legal or biological meaning, for example, 'in danger of', 'likely' and 'foreseeable future.' The resulting legal wrangling costs too much time and money. The phrase 'significant portion of its range' is particularly problematic, prompting lengthy arguments in courts and countless pages of legal documents. In the past decade, dozens of challenges to listing decisions have focused on the term.

To be more effective, ESA assessments should incorporate what is widely accepted as the most authoritative system for systematically categorizing species by extinction risk: the Red List of Threatened Species maintained by the International Union for Conservation of Nature (IUCN), the largest global coalition of environmental organizations. This list uses objective, quantitative criteria that account for uncertainty and gaps in data. For example, species with a population size of fewer than 50 mature individuals are classified as critically endangered.
Regulators in other countries have taken note. Canada's ESA equivalent, the Species at Risk Act, uses the IUCN Red List system to determine extinction risk; individual species are then listed by explicitly taking into account other societal considerations, such as the perceived economic or even political costs associated with listing. This separates the science and policy aspects of setting conservation priorities. A similar practice might help to unblock the current logjam at the US Fish and Wildlife Service.

Most of the agency's decisions to review how a species should be listed are initiated not because of scientific uncertainty, but because of lawsuits brought by individuals or interest groups hoping to alter legal protection for particular species. Costly legal arguments caused by ambiguities in the listing process leave the agency with few resources for proactive steps that would help it to fulfil its primary mission to save species.

\section{JOHN TSCHIRHART Account for economics}

\section{Professor of economics, University of Wyoming}

Economic impacts of conservation plans cause many of the controversies surrounding the ESA. To manage endangered species effectively, we need sophisticated, integrated models that evaluate ecosystem and economic trade-offs. If these describe unanticipated economic beneficiaries, conservation plans could have unexpected champions.

Many governments use complex economic models called computable general equilibrium models. These can predict how a tax or tariff policy might affect various industries and how those effects would ripple out to other industries and to consumers' incomes. Few models consider the effects of conservation policies. Those that do are usually narrow in scope and restricted to a single species.

That is not surprising: ecosystem models that cover multiple species and their effects on each other are relatively new, yet they can reveal unexpected insights. Such large-scale general ecosystem models have, for example, forecast that an increase in pollock (Theragra) levels in Alaskan fisheries could decrease levels of sea otters, even though the species do not interact directly ${ }^{3}$. More pollock swells popula-

\section{"The biggest benefits will come when ecosystem models are integrated into economic ones."} tions of their predators, sea lions, which in turn boosts populations of their predators, killer whales, which also feed on otters. Although most ecological modelling considers only two or three species at once, integrated models are emerging, and these will be essential to manage endangered species effectively.

The biggest benefits will come when ecosystem models are integrated into economic ones. Ecological and economic variables are, after all, interdependent. For instance, policies that keep chicken-farm waste from reaching rivers might produce economic benefits in the recreation and fishing industries. Pollock-fishing losses could be outweighed by gains in tourism as more sightseers go to watch sea lions cavort. Economic modelling will not always show net gains for conservation policies, but the current models rarely capture gains at all.

1. Scott, J. M., Goble, D. D., Svancana, L. K. \& Pidgorna, A. in The Endangered Species Act at Thirty Vol. 1 (eds Goble, D. D., Scott, J. M. \& Davis, F. W.) Ch. 2 (Island, 2006).

2. Suckling, K. Measuring the Success of the Endangered Species Act (Centre for Biological Diversity, 2006).

3. Finnoff, D. \& Tschirhart, J. Res. Energy Econ. 30, 91-114 (2008). 